\title{
A new MCDM-based approach using BWM and SAW for optimal search model
}

\author{
Alireza Sotoudeh-Anvaria, Seyed Jafar Sadjadi ${ }^{b^{*}}$, Seyed Mohammad Hadji Molana ${ }^{\mathrm{a}}$ and Soheil \\ Sadi-Nezhad ${ }^{a}$
}

${ }^{a}$ Department of Industrial Engineering, Science and Research Branch, Islamic Azad University, Tehran, Iran ${ }^{b}$ Department of Industrial Engineering, Iran University of Science and Technology, Tehran, Iran

\begin{tabular}{l}
\hline C H R O N I C L E \\
\hline Article history: \\
Received October 1, 2017 \\
Received in revised format: \\
January 8, 2017 \\
Accepted February 21, 2018 \\
Available online \\
February 21, 2018 \\
\hline Keywords: \\
Search problem \\
Best-worst method \\
Subjective weighting technique \\
Simple additive weighting
\end{tabular}

\section{Introduction}

Search theory (ST) is the study of how to utilize the resources when attempting to find a target whose location is not known precisely (Stone, 2013). Search for lost or hidden objects happens for various real cases. Widespread applications are detection of secret hostile targets, detection of land mine and rescuing lost people (Kriheli et al., 2016; Sotoudeh-Anvari et al., 2018). ST has various models and among them, optimal search model (Ross, 1983) is one of the most broadly used forms (Benkoski et al., 1991). In the multiobjective optimal search model a single target is located in one of possible locations. The number of locations is known and the target cannot move. For each location, we determine the search cost, the search time and the probability that our target is in a given location. Also the probability that a target will be detected on one look is known (also known as overlook probability).

\footnotetext{
* Corresponding author. Tel.: +98-21-7724-129

E-mail address: sjsadjadi@iust.ac.ir (S.J. Sadjadi)

C 2018 by the authors; licensee Growing Science, Canada. doi: $10.5267 /$ j.dsl.2018.2.001
} 
The aim of this problem is to gain a search policy that optimize expected cost and time in search process (Ross, 1983). Various approaches such as dynamic programming have been introduced for solving this problem (Black, 1965). But usually these approaches are complex and need significant amount of computations (Benkoski et al., 1991; Kadane, 2015; Stone, 1976; Levner, 1994). On the other hand, first, Sotoudeh-Anvari et al. (2018) formulated the optimal search problem as an MCDM problem. The aim of MCDM model of search problem is to rank the locations in the presence of some decision factors such as search cost, search time, the probability of detecting and overlook probability. It is important to mention that it cannot be claimed that the MCDM framework has the same characteristics as the original optimal search model (Ross, 1983), but it can provide important points for initial decision.

Sotoudeh-Anvari et al. (2018) suggested a new MCDM approach which was composed by Entropy method to weight criteria and Technique for Order of Preference by Similarity to Ideal Solution (TOPSIS) and Complex Proportional Assessment (COPRAS) to rank the locations in a search problem. Although Entropy technique as an objective weighting method has its advantages, it has some limitations too. First of all, many researchers believe that in the real problems, weights of decision factors are always subjective, returning the judgment of decision maker (DM) (Zavadskas \& Podvezko, 2016; Wang \& Chang, 2007). Moreover, some researchers such as Jing et al. (2012) pointed out that objective weighting methods can sometimes generate an opposite result to reasoning. Among the subjective methods, AHP is the most extensively used approach. However, AHP suffers from various drawbacks in this field. AHP is criticized for the high difficulty owing to pairwise comparisons and the lack of consistency (Rezaei 2015; Løken, 2007). Fortunately, Rezaei (2015) mentioned that these problems can be alleviated with a more structured comparison approach and introduced a new MCDM method called BWM. In this paper, BWM is used for determining the weights of the decision factors and then rankings of the locations are obtained by SAW. To our knowledge, this study presents the first usage of BWM for weighting of selection factors in search context. Also we extend SAW to rank the locations since SAW has a clear logic and very easy calculation procedure that provides the rationale of human option. Let us recall that Sotoudeh-Anvari et al. (2018) applied TOPSIS and COPRAS to tackle optimal search problem and obtained suitable results, but application of SAW in this context is new.

The reminder of our work is ordered as follows. In Section 2, a background of MCDM paradigm, BWM and SAW is presented. Section 3 focuses on the suggested MCDM-based model for search problem. A numerical case is elucidated in Section 4. Finally, the conclusion and future researches are reviewed in Section 5 .

\section{Methods}

Here, a background of MCDM paradigm and the key methods, namely BWM and SAW are introduced.

\subsection{MCDM paradigm}

MCDM is one of the most popular branches of decision theory. Although a large number of MCDM techniques have been introduced, each of the them has its own characteristics and none of these methods can be selected as the best method (Løken, 2007; Mulliner et al., 2016). Nevertheless, some MCDM methods are more suitable for a given problem. On the other hand, because of the availability of many MCDM methods, selection of a suitable MCDM method can be considered as an MCDM problem (Triantaphyllou, 2000; Bernroider and Stix, 2007). On the basis of various selection factors such as simplicity, validity, computation time, problem structure (number of alternatives or criteria), final result, and rank reversal, one can deduce that COPRAS, TOPSIS and SAW can be considered as the most efficient as well as the most user friendly MCDM method in many fields (Dey et al., 2016; Mousavi-Nasab \& Sotoudeh-Anvari, 2017; Mulliner et al., 2016, Mousavi-Nasab \& Sotoudeh-Anvari, 2018; Chatterjee et al., 2011). It is very important to mention that this finding must be extended 
cautiously and on the basis of the need of the given problem. For example, COPRAS, TOPSIS and SAW are compensatory methods and in these methods tradeoff among decision criteria is permissible. But in non-compensatory methods, a bad score in a decision factor cannot be compensated by a good score for the other decision factor (Mulliner et al., 2016). Clearly, in such cases, the appropriate MCDM technique should be selected according to problem structure. More formally, compatibility with the aim of problem is one of the most essential factors in choosing an MCDM approach (Roy, 1990; Mulliner et al., 2016). Also some researchers such as Løken (2007), Mulliner et al. (2016), Wang et al. (2016), Mousavi-Nasab and Sotoudeh-Anvari (2017) and Garg and Jain (2017) suggested that more than one MCDM technique should be used to a problem to obtain a more comprehensive and safe decision. For more about MCDM methods, reader is referred to Hobbs and Horn (1997), Ginevičius and Zubrecovas (2009), Mousavi-Nasab and Sotoudeh-Anvari (2017), Serrai et al. (2017), and Løken (2007).

Irrespective of preferred MCDM method for problem tackling, the key step is to gain the decision factor weights. There are different approaches for determining the criteria weights in MCDM techniques, including 1) subjective method such as AHP, 2) objective method such as Entropy method, and 3) the combination method. In subjective weighting approach, the weights are obtained according to a DM's opinions. On the other hand, objective weights are obtained according to the information of decision matrix on the basis of mathematical models. The combination methods compute the weights by DM's judgment and decision matrix data (Wang \& Luo, 2010). Obviously, each weighting method has its own advantages and drawbacks. However, subjective weights return the opinions of DMs with the practical experience in that context and therefore, in nearly all real problems subjective weights are useful (Wang \& Chang, 2007). Among the subjective methods, AHP has an extensive popularity for weighting via pairwise comparison technique. But Løken (2007) pointed out that there are various criticisms against AHP. For example, inconsistency is the key challenge in pairwise comparison approaches, which often takes place in practice (Rezaei, 2015). Also AHP is too time-consuming when the amount of decision factors is large (Løken, 2007). Rezaei (2015) revealed that the root of this problem is in the unstructured comparisons and proposed a new MCDM technique, namely BWM that gains the criteria weights in a different way. In the next sub-section, more explanation about BWM is provided.

\subsection{Best-Worst Method}

Although there are several MCDM techniques, the steps of these methods often are similar, including problem definition, alternatives selection, criteria selection, decision matrix construction, criteria weight determination, and ranking (Terrados et al., 2009). Because criteria weights play a very important role in the ranking of options, a vital task is to determine the weights of decision factors. There are several MCDM techniques that can be employed to weight criteria, the most conventional of which are AHP. This technique uses pairwise comparisons of the selection criteria on the basis of DM's opinion. But as mentioned, inconsistency is a complicated problem to the pairwise comparison approaches (Rezaei, 2015). To solve this problem, Rezaei (2015) suggested BWM that is always consistent. In BWM, DM should identify the most desirable criterion and the least desirable criterion and make pairwise comparisons between these criteria and the other criteria. Finally, a maximin model is resulted to compute the weights of selection criteria (Mou et al., 2016). Clearly, in BWM fewer comparisons compared to AHP are needed and mathematically, the comparisons in BWM are reduced from $n(n-1) / 2$ to $2 n-3$ with $n$ decision factors (Rezaei, 2015). Furthermore, BWM provides a structured pairwise comparison which generates consistent outcomes (Rezaei, 2016). For achieving consistency and simplicity, compared to the conventional AHP, BWM has been employed broadly in diverse applications such as sustainable oil supply chain management (Ahmad et al., 2017), healthcare management (Mou et al., 2016), investment opportunities (Askarifar et al., 2018), web service selection (Serrai et al., 2017) medical tourism development (Abadi et al., 2018), technological innovation development (Ghaffari et al., 2017), research and development ( Salimi and Rezaei, 2018) green supplier selection (Gupta and Barua, 2017) and urban sewage sludge (Ren et al., 2017). 


\subsection{Simple Additive Weight}

Literature review shows that SAW is the simplest MCDM method to understand and to apply (Serrai et al., 2017). Moreover, this method is the most frequently used MCDM technique (Salehi \& Izadikhah, 2014) and can be employed as a benchmark to evaluate the results of the other MCDM approaches (Wang et al., 2016).

SAW consists of five steps as follows,

Step 1: Normalize the decision matrix according to Model (1)

$$
r_{i j}= \begin{cases}x_{i j} / x_{j}^{+} & j \in \Omega_{\max } \\ x_{j}^{-} / x_{i j} & j \in \Omega_{\min }\end{cases}
$$

In Model (1), $\Omega_{\max }$ and $\Omega_{\min }$ are sets of positive and negative decision attributes, respectively.

Step 2: Identify the weight of decision factors.

Step 3: Compute the ranking value on the basis of Model (2):

$$
S_{i}=\sum_{j=1}^{n} w_{j} r_{i j}
$$

The bigger the $S_{i}$, the better the option is.

\section{Suggested model on the basis of BWM and SAW for search problem}

Now, a new MCDM methodology as depicted in Fig.1 is proposed for search problem. Each of these steps is introduced below:

In the first step, the potential locations of lost or hidden target and decision criteria which will be employed in the assessment process via literature and discussions with DMs are determined. Although different selection factors can be important while considering the optimal search problem, in this study, the selection attributes for the ranking of locations can be gained from the Fiedrich et al. (2000), Najafi et al. (2013) and Gutjahr and Nolz (2016). Therefore, four criteria are selected, including search cost, search time, probability that the target is in a given location and finally, the probability that a target to be detected on one look.

In the second stage, the weight of selection criteria is obtained using BWM. According to Rezaei (2015) and Rezaei (2016), BWM consists of five steps as follows.

Step 1: Define the set of decision factors.

In this step, DM introduces $n$ decision factors, namely $\left\{c_{1}, c_{2}, \ldots c_{n}\right\}$ to make a decision.

Step 2: Specify the best decision factor and the worst decision factor. 
The best decision factor is the most preferred attribute and the worst decision factor is the least preferred attribute.

Step 3: Identify the preference of the best decision factor over the other decision factors. In this step, integers can only be used. The best-to-others (BO) vector is:

$A_{B}=\left(a_{B 1}, a_{B 2}, \ldots a_{B n}\right)$

In the $\mathrm{BO}$ vector, $a_{B j}$ represents the preference of the best factor $B$ over selection factor $j$ and $a_{B B}=1$.

Step 4: Identify the preference of all decision factors over the worst decision factor. In this step, integers can only be used. The others-to-worst (OW) vector is:

$A_{W}=\left(a_{1 W}, a_{2 W}, \ldots a_{n W}\right)^{T}$

In OW vector, $a_{j W}$ represents the preference of selection factor $j$ over the worst decision factor $W$ and $a_{W W}=1$.

Step 5: Compute the best possible weights $\left(\mathrm{w}_{1}^{*}, \mathrm{w}_{2}^{*}, \ldots, \mathrm{w}_{n}^{*}\right)$ by Model (3) as follows:

$$
\min \max _{j}\left\{\left|\frac{w_{b}}{w_{j}}-a_{B j}\right|,\left|\frac{w_{j}}{w_{W}}-a_{j W}\right|\right\}
$$

S.t.

$\sum_{j} w_{j}=1$

$w_{j} \geq 0 \quad$ for all $j$

Model (3) can be converted to Model (4) as follows:

$$
\begin{aligned}
& \min \xi \\
& \left|\frac{w_{B}}{w_{j}}-a_{B j}\right| \leq \xi \text { for all } j \\
& \left|\frac{w_{j}}{w_{W}}-a_{j W}\right| \leq \xi \text { for all } j \\
& \sum_{j} w_{j}=1 \\
& w_{j} \geq 0 \quad \text { for all } j
\end{aligned}
$$

Solving Model (4), the best possible weights $\left(\mathrm{w}_{1}^{*}, \mathrm{w}_{2}^{*}, \ldots, \mathrm{w}_{n}^{*}\right)$ and $\xi$ are achieved. Also the consistency ratio $(\mathrm{CR})$ can be calculated on the basis of $\operatorname{Model}(5)$ :

Consistency ratio $=\frac{\xi}{\text { Consistency Index }}$

The "Consistency Index" can be seen in Table 1 (Rezaei, 2015; Rezaei, 2016). 
Table 1

Consistency Index

\begin{tabular}{llllllllll}
\hline$a_{B W}$ & 1 & 2 & 3 & 4 & 5 & 6 & 7 & 8 & 9 \\
\hline Consistency Index & 0 & 0.44 & 1 & 1.63 & 2.3 & 3 & 3.73 & 4.47 & 5.23 \\
\hline
\end{tabular}

A CR close to zero indicates more consistency and CR close to one indicates less consistency (Rezaei, 2016). As mentioned, always the result of BWM is consistent. However, Rezaei (2015) pointed out that in AHP, CR is used to verify the validity of comparisons, but CR in BWM is used to determine the degree of reliability.

Finally, location rankings are identified by SAW.

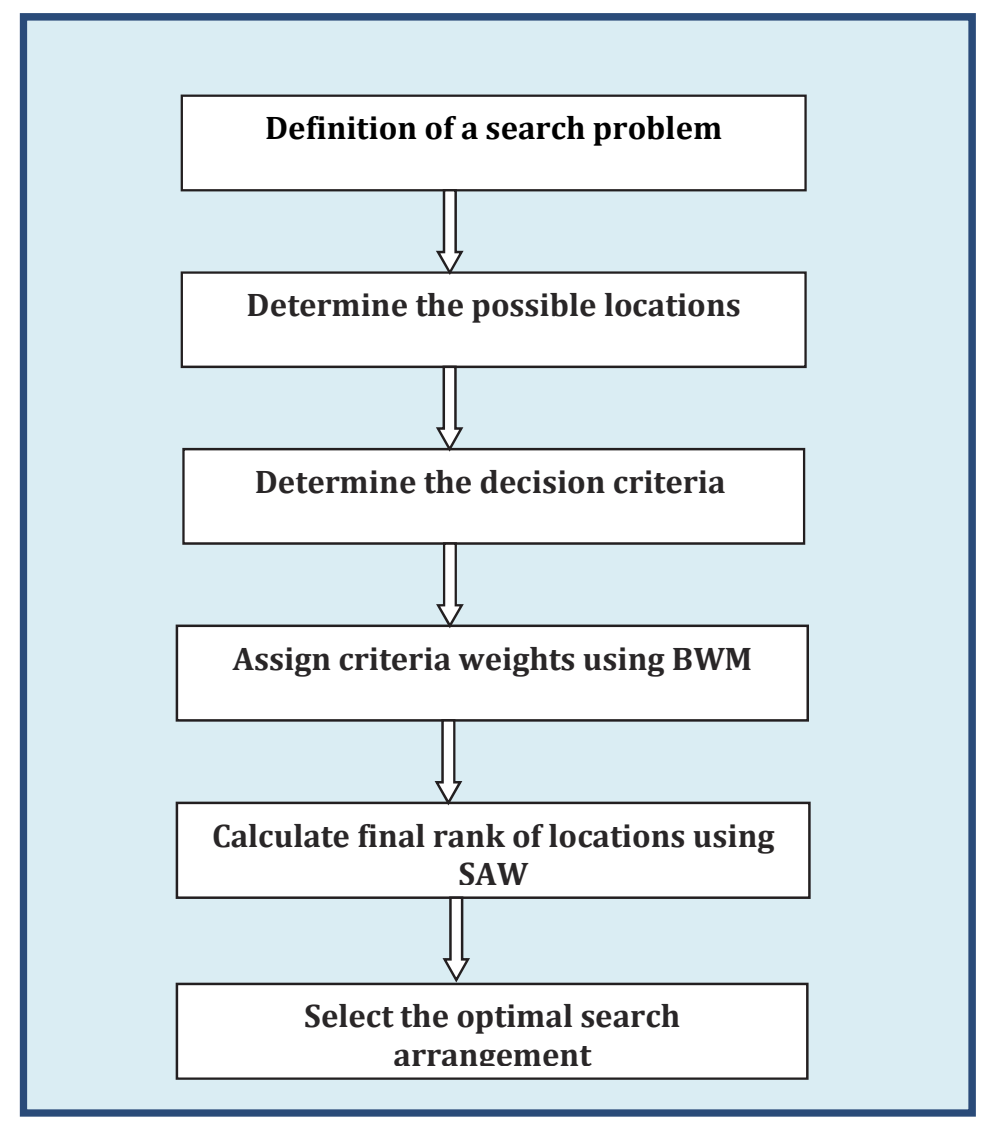

Fig. 1. Flowchart of the suggested model for search problem

\section{Numerical example}

The application of the suggested MCDM-based model in this numerical case will signify its validity. After an earthquake, a search team is organized to search a missing family. Probably, they have been confined in one of the following locations: a cottage (location 1), a forest (location 2), a mountain (location 3), a shopping center (location 4) and amusement park (location 5). The probability that they are in each of these locations, overlook probability, the search cost and the search time of these locations are provided as decision matrix in Table 2 . The objective of the aforementioned problem is the ranking of these five locations for search operation. 
Table 2

Decision matrix

\begin{tabular}{lllll}
\hline & Search cost $\left(\mathrm{C}_{1}\right)$ & Search time $\left(\mathrm{C}_{2}\right)$ & Probability of finding $\left(\mathrm{C}_{3}\right)$ & Overlook probability $\left(\mathrm{C}_{4}\right)$ \\
\hline Location 1 & 24.5 & $19.5 \mathrm{~h}$ & $22 \%$ & $20 \%$ \\
Location 2 & 25.5 & $17.5 \mathrm{~h}$ & $20 \%$ & $35 \%$ \\
Location 3 & 29 & $16 \mathrm{~h}$ & $21 \%$ & $15 \%$ \\
Location 4 & 28 & $14.5 \mathrm{~h}$ & $18 \%$ & $20 \%$ \\
Location 5 & 26 & $18.5 \mathrm{~h}$ & $19 \%$ & $25 \%$ \\
\hline
\end{tabular}

In the first step, the weight of decision criteria should be determined. In this study, the weights are obtained by BWM as follows:

The first stage in BWM is specified the best selection factor and the worst selection factor. In this problem, "probability of finding $\left(\mathrm{C}_{3}\right)$ " and "search cost $\left(\mathrm{C}_{1}\right)$ " is selected as the best and the worst criteria, respectively. In the second stage, the preferences of the best factor over the criteria should be determined by integers (as can be found in Table 3 ).

\section{Table 3}

$\mathrm{BO}$ vector

\begin{tabular}{llll}
\hline Criteria & $C_{1}$ & $C_{2}$ & $C_{4}$ \\
\hline Best criterion: $C_{3}$ & 4 & 3 & 2 \\
\hline
\end{tabular}

In the third step, the preferences of criteria over the least important factor should be determined by integers (as can be found in Table 4).

\section{Table 4}

OW vector

\begin{tabular}{llll}
\hline Criteria & $C_{1}$ & $C_{3}$ & $C_{4}$ \\
\hline Worst criterion: $C_{1}$ & 2 & 4 & 3 \\
\hline
\end{tabular}

According to Table 3 and Table 4 and by solving Model (4), the weights can be gained as $w_{1}=0.1036$ , $w_{2}=0.1706, w_{3}=0.4514, w_{4}=0.2742$ and $\xi=0.354$. On the basis of Model (5), we have $C R=0.21$ that this indicates a very good degree of reliability. According to this numerical case, the ease and consistency of BWM is clear.

Now, SAW is used to rank these locations. According to SAW, the ranking of locations is gained as 31-4-5-2. On the other words, the aforementioned locations are searched in order 3-1-4-5-2 until the family is detected. On the other hand, when the same search problem is worked out by TOPSIS and COPRAS, the arrangement of locations is achieved as 3-1-4-5-2 too. Clearly, the ranking of locations exactly match in SAW, COPRAS and TOPSIS. This numerical example denotes that the suggested model is very easy and produces comparable consequence with other MCDM approaches.

\section{Conclusion}

In this paper, we have suggested a new MCDM-based framework for solving optimal search problem. First, BWM was applied to obtain the criteria weights and then SAW is used to find the final ranking. Compared to AHP, BWM has various advantages such as very structured pairwise comparison as well as trustworthy outcomes. Moreover, the comparison times in BWM was reduced considerably. Hence, 
BWM can be used well as a subjective technique for weighting of decision factors in search problem. Fortunately, the suggested approach is very straightforward and can be developed to handle other MCDM problems.

As a future study, BWM will be extended to various fuzzy environments and we will employ this fuzzy BWM in a number of real problems. Also the possible shortcomings of BWM will be discussed.

\section{References}

Abadi, F., Sahebi, I., Arab, A., Alavi, A., \& Karachi, H. (2018). Application of best-worst method in evaluation of medical tourism development strategy. Decision Science Letters, 7(1), 77-86.

Ahmad, W. N. K. W., Rezaei, J., Sadaghiani, S., \& Tavasszy, L. A. (2017). Evaluation of the external forces affecting the sustainability of oil and gas supply chain using Best Worst Method. Journal of Cleaner Production, 153, 242-252.

Askarifar, K., Motaffef, Z., \& Aazaami, S. (2018). An investment development framework in Iran's seashores using TOPSIS and best-worst multi-criteria decision making methods. Decision Science Letters, 7(1), 55-64.

Benkoski, S. J., Monticino, M. G., \& Weisinger, J. R. (1991). A survey of the search theory literature. Naval Research Logistics (NRL), 38(4), 469-494.

Bernroider, E., \& Stix, V. (2007). A method using weight restrictions in data envelopment analysis for ranking and validity issues in decision making. Computers \& Operations Research, 34(9), 2637 2647.

Black, W. L. (1965). Discrete sequential search. Information and control, 8(2), 159-162.

Chatterjee, P., Athawale, V. M., \& Chakraborty, S. (2011). Materials selection using complex proportional assessment and evaluation of mixed data methods. Materials \& Design, 32(2), 851860.

Dey, B., Bairagi, B., Sarkar, B., \& Sanyal, S. K. (2016). Multi objective performance analysis: A novel multi-criteria decision making approach for a supply chain. Computers \& Industrial Engineering, 94, 105-124.

Fiedrich, F., Gehbauer, F., \& Rickers, U. (2000). Optimized resource allocation for emergency response after earthquake disasters. Safety science, 35(1-3), 41-57.

Garg, R., \& Jain, D. (2017). Fuzzy multi-attribute decision making evaluation of e-learning websites using FAHP, COPRAS, VIKOR, WDBA. Decision Science Letters, 6(4), 351-364.

Ghaffari, S., Arab, A., Nafari, J., \& Manteghi, M. (2017). Investigation and evaluation of key success factors in technological innovation development based on BWM. Decision Science Letters, 6(3), 295-306.

Ginevičius, R., \& Zubrecovas, V. (2009). Selection of the optimal real estate investment project basing on multiple criteria evaluation using stochastic dimensions. Journal of business economics and management, 10(3), 261-270.

Gupta, H., \& Barua, M. K. (2017). Supplier selection among SMEs on the basis of their green innovation ability using BWM and fuzzy TOPSIS. Journal of Cleaner Production, 152, 242-258.

Gutjahr, W. J., \& Nolz, P. C. (2016). Multicriteria optimization in humanitarian aid. European Journal of Operational Research, 252(2), 351-366.

Hobbs, B. F., \& Horn, G. T. (1997). Building public confidence in energy planning: a multimethod MCDM approach to demand-side planning at BC gas. Energy policy, 25(3), 357-375.

Jing, Y. Y., Bai, H., \& Wang, J. J. (2012). A fuzzy multi-criteria decision-making model for CCHP systems driven by different energy sources. Energy Policy, 42, 286-296.

Kadane, J. B. (2015). Optimal discrete search with technological choice. Mathematical Methods of Operations Research, 81(3), 317-336.

Kriheli, B., Levner, E., \& Spivak, A. (2016). Optimal search for hidden targets by unmanned aerial vehicles under imperfect inspections. American Journal of Operations Research, 6(02), 153. 
Levner, E. (1994). Infinite-horizon Scheduling Algorithms for Optimal Search for Hidden Objects. International transactions in operational research, 1(2), 241-250

Løken, E. (2007). Use of multicriteria decision analysis methods for energy planning problems. Renewable and Sustainable Energy Reviews, 11(7), 1584-1595.

Mousavi-Nasab, S. H., \& Sotoudeh-Anvari, A. (2017). A comprehensive MCDM-based approach using TOPSIS, COPRAS and DEA as an auxiliary tool for material selection problems. Materials \& Design, 121, 237-253.

Mousavi-Nasab, S. H., \& Sotoudeh-Anvari, A. (2018). A new multi-criteria decision making approach for sustainable material selection problem: A critical study on rank reversal problem. Journal of Cleaner Production.

Mou, Q., Xu, Z., \& Liao, H. (2016). An intuitionistic fuzzy multiplicative best-worst method for multicriteria group decision making. Information Sciences, 374, 224-239.

Mulliner, E., Malys, N., \& Maliene, V. (2016). Comparative analysis of MCDM methods for the assessment of sustainable housing affordability. Omega, 59, 146-156.

Najafi, M., Eshghi, K., \& Dullaert, W. (2013). A multi-objective robust optimization model for logistics planning in the earthquake response phase. Transportation Research Part E: Logistics and Transportation Review, 49(1), 217-249.

Ren, J., Liang, H., \& Chan, F. T. (2017). Urban sewage sludge, sustainability, and transition for EcoCity: Multi-criteria sustainability assessment of technologies based on best-worst method. Technological Forecasting and Social Change, 116, 29-39.

Rezaei, J. (2015). Best-worst multi-criteria decision-making method. Omega, 53, 49-57.

Rezaei, J. (2016). Best-worst multi-criteria decision-making method: Some properties and a linear model. Omega, 64, 126-130.

Ross, S. M. (1983). Introduction to stochastic dynamic programming. Academic press.

Roy, B. (1990). The outranking approach and the foundations of ELECTRE methods. In Readings in multiple criteria decision aid (pp. 155-183). Springer, Berlin, Heidelberg.

Salehi, A., \& Izadikhah, M. (2014). A novel method to extend SAW for decision-making problems with interval data. Decision Science Letters, 3(2), 225-236.

Salimi, N., \& Rezaei, J. (2018). Evaluating firms' R\&D performance using best worst method. Evaluation and program planning, 66, 147-155.

Serrai, W., Abdelli, A., Mokdad, L., \& Hammal, Y. (2017). Towards an efficient and a more accurate web service selection using MCDM methods. Journal of Computational Science, 22, 253-267.

Sotoudeh-Anvari, A., Sadjadi, S.J., Molana, S.M.H., \& Sadi-Nezhad, S. (2018). A stochastic multiobjective model based on the classical optimal search model for searching for the people who are lost in response stage of earthquake. Scientia Iranica (in press)

Stone, L. D. (1976). Theory of optimal search (Vol. 118). Elsevier.

Stone, L. D. (2013). Search theory. Encyclopedia of Operations Research and Management Science, 1366-1378.

Terrados, J., Almonacid, G., \& PeRez-Higueras, P. (2009). Proposal for a combined methodology for renewable energy planning. Application to a Spanish region. Renewable and Sustainable Energy Reviews, 13(8), 2022-2030.

Triantaphyllou, E. (2000). Multi-criteria decision making methods. In Multi-criteria decision making methods: A comparative study (pp. 5-21). Springer, Boston, MA.

Wang, T. C., \& Chang, T. H. (2007). Application of TOPSIS in evaluating initial training aircraft under a fuzzy environment. Expert Systems with Applications, 33(4), 870-880.

Wang, Y. M., \& Luo, Y. (2010). Integration of correlations with standard deviations for determining attribute weights in multiple attribute decision making. Mathematical and Computer Modelling, 51(1-2), 1-12.

Wang, P., Zhu, Z., \& Wang, Y. (2016). A novel hybrid MCDM model combining the SAW, TOPSIS and GRA methods based on experimental design. Information Sciences, 345, 27-45. 
Zavadskas, E. K., \& Podvezko, V. (2016). Integrated determination of objective criteria weights in MCDM. International Journal of Information Technology \& Decision Making, 15(02), 267-283.

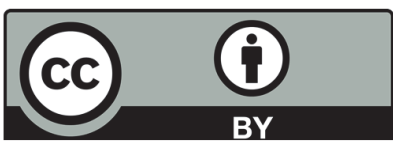

(C) 2018 by the authors; licensee Growing Science, Canada. This is an open access article distributed under the terms and conditions of the Creative Commons Attribution (CC-BY) license (http://creativecommons.org/licenses/by/4.0/). 